\title{
BMJ Open Engaging patients through open notes: an evaluation using mixed methods
}

\author{
Tobias Esch, ${ }^{1,2}$ Roanne Mejilla, ${ }^{1}$ Melissa Anselmo, ${ }^{1}$ Beatrice Podtschaske, ${ }^{3}$ \\ Tom Delbanco, ${ }^{1}$ Jan Walker ${ }^{1}$
}

To cite: Esch T, Mejilla R, Anselmo M, et al. Engaging patients through open notes: an evaluation using mixed methods. BMJ Open 2016;6: e010034. doi:10.1136/ bmjopen-2015-010034

\section{- Prepublication history and additional material is available. To view please visit the journal (http://dx.doi.org/ 10.1136/bmjopen-2015- 010034)}

Received 18 September 2015 Revised 16 November 2015 Accepted 2 December 2015

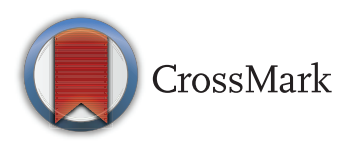

${ }^{1}$ Division of General Medicine and Primary Care, Harvard Medical School, Beth Israel Deaconess Medical Center, Boston, Massachusetts, USA ${ }^{2}$ Division of Integrative Health Promotion, Coburg University of Applied Sciences, Coburg, Germany

${ }^{3}$ Department of Health Policy and Management, Harvard School of Public Health, Boston, Massachusetts, USA

Correspondence to Dr Tobias Esch; tesch@bidmc.harvard.edu

\section{ABSTRACT}

Objectives: (A) To gain insights into the experiences of patients invited to view their doctors' visit notes, with a focus on those who review multiple notes; (B) to examine the relationships among fully transparent electronic medical records and quality of care, the patient-doctor relationship, patient engagement, selfcare, self-management skills and clinical outcomes.

Design: Mixed methods qualitative study: analyses of survey data, including content analysis of free-text answers, and quantitative-descriptive measures combined with semistructured individual interviews, patient activation measures, and member checks.

Setting: Greater Boston, USA.

Participants: Patients cared for by primary care physicians (PCPs) at the Beth Israel Deaconess Medical Center who had electronic access to their PCP visit notes. Among those submitting surveys, 576 freetext answers were identified and analysed (414 from female patients, 162 from male patients; $23-88$ years). In addition, 13 patients (9 female, 4 male; $58-$ 87 years) were interviewed.

Results: Patient experiences indicate improved understanding (of health information), better relationships (with doctors), better quality (adherence and compliance; keeping track) and improved self-care (patient-centredness, empowerment). Patients want more doctors to offer access to their notes, and some wish to contribute to their generation. Those patients with repeated experience reviewing notes express fewer concerns and more perceived benefits.

Conclusions: As the use of fully transparent medical records spreads, it is important to gain a deeper understanding of possible benefits or harms, and to characterise target populations that may require varying modes of delivery. Patient desires for expansion of this practice extend to specialty care and settings beyond the physician's office. Patients are also interested in becoming involved actively in the generation of their medical records. The OpenNotes movement may increase patient activation and engagement in important ways.

\section{INTRODUCTION}

Easy access to personal health information has long been on the 'wish lists' of patients and their advocates, ${ }^{1-5}$ and modern health information technology, the Internet, and

\section{Strengths and limitations of this study}

- This study uses rigorous qualitative methodology and descriptive quantitative measures to understand the experience of patients who both utilise health services frequently and read their primary care physician's visit notes online.

- It compares free-text survey responses from samples of patients who frequently read their encounter notes to responses from those who made little use of this option.

- It draws on face-to-face interviews with an information-rich, purposive sample of patients who had read notes from many visits. The results suggest that patients who read their notes are actively engaged in their care and have a better understanding of their health and care, but the generalisability of the findings is limited because patients who were cared for in a single institution differed from a majority of patients nationally by virtue of having registered on secure electronic patient portals.

secure patient portals have dramatically increased the possibilities for patients. ${ }^{6-9}$ In the USA, the Health Insurance Portability and Accountability Act (HIPAA), enacted in 1996, affords patients the right to access their clinical information and medical records, except in rare circumstances primarily involving major mental disorders. However, until recently, it has been difficult for patients to gain access, and only rarely do they review the notes their clinicians write following encounters, both in the ambulatory setting and on hospital wards. Today, electronic health records (EHRs), coupled to patient-facing, secure Internet portals, facilitate access if providers decide to offer it, and such portals are spreading rapidly, partly in response to federal incentives. ${ }^{10-13}$ More than five million patients in the USA are now registered on portals that offer ready and secure access electronically to their clinicians' notes.

Many argue that EHRs should support transparent clinical communication with 
patients, ${ }^{14-16}$ but the practice remains controversial. ${ }^{17-24}$ Doctors worry about disturbances to their workflow and fear frightening some patients. At a time when electronic information breaches are widely publicised, some worry that general concern about loss of privacy may lead patients to withhold information or refrain from visiting doctors when care may be indicated. On the other hand, easy access to records may encourage underserved populations to engage more actively with the healthcare system. ${ }^{25} 26$

Secure electronic patient portals offer the opportunity to improve patient education, ${ }^{27} 28$ the management of chronic conditions ${ }^{29} 30$ and efficiency of care ${ }^{31}$ by shifting care from a prime focus in the doctor's office towards more integrated perspectives that include patients' daily lives, homes, caregivers and families. ${ }^{32-35}$ Transparent hospital records may promote more information sharing in clinician-patient communication. ${ }^{36}{ }^{37}$ Overall, information gaps may be narrowed, thereby facilitating better continuity and integration of care ${ }^{38-40}$ Patients appear to value the convenience of easy and flexible access, ${ }^{41}$ and individuals with poor health status may, in particular, benefit by being able to share their information with family members and other informal caregivers. ${ }^{42} 43$

OpenNotes, a rapidly expanding national movement in the USA that encourages clinicians to offer patients ready access to their encounter notes, began as a demonstration and evaluation study in 2010, with 105 volunteer primary care physicians (PCPs) and 19000 of their patients in Boston, rural Pennsylvania, and the Seattle inner city. ${ }^{44-47}$ Notified automatically via a secure email message when a note was signed, patients were invited to review their doctors' notes, and they were again encouraged to do so prior to a next scheduled visit. Results from the 1-year evaluation were striking and attracted considerable attention from professional groups and consumers. ${ }^{48}$ Four of five patients read their note(s); two-thirds of those surveyed a year after the experiment started reported potentially important clinical benefits; $99 \%$ of the patients completing surveys wanted the practice to continue, whether or not they chose to read the notes; and $85 \%$ indicated that access would be important for their future choice of a provider or system. Perhaps most strikingly, at the end of the study, no doctor chose to discontinue the practice. Since this study, the findings have been replicated in several other settings, including hospitalised patients, ${ }^{49-51}$ and today the entire Veterans Administration health system, many major academic health centres, large health systems and increasing numbers of smaller institutions in urban and rural settings in the USA are adopting the practice (http://www.myopennotes.org). Although percentages of patients reading their notes may differ, study results indicate that patients both value and benefit from online access to clinical notes, and adherence for some medications may indeed improve. ${ }^{52}$

Patients can read their notes at home or wherever they want, that is, asynchronously and repeatedly, and can readily share their notes with people of their choice by downloading them and forwarding them, or by inviting others to read them on a computer, tablet or smartphone. Some users now have 5 years of experience with open notes, and many patients have become frequent users. We decided to revisit this 'expert' population and to gather further insights through a systematic analysis of free-text comments offered in the patient surveys, and through in-depth interviews with individuals with a heavy burden of illness who reviewed their notes frequently.

\section{Objectives of this study}

1. To characterise the patient experience with open notes and, in particular, to identify and describe themes that emerge from patients making primary care visits and reading their notes with high frequencies;

2. To examine whether and how open encounter notes are linked to patient engagement;

3. To evaluate from the frequent user's perspective how open encounter notes/transparency relates to selfcare/self-management, patient outcomes, quality of care and the patient-physician relationship.

\section{METHODS}

This study used a mixed methods research design (figure 1). We examined free-text responses and patient characteristics from the Beth Israel Deaconess Medical Center (BIDMC) survey respondents participating in 2010-2011, with the quantitative findings published in 2012. ${ }^{48}$ Baseline surveys $(n=4545)$ were collected to examine the preintervention study population characteristics and expectations before exposure to open notes. ${ }^{45}{ }^{46}$ Patients were eligible if they had been registered on the patient Internet portal for at least 1 year before the start of the study, and if their PCPs agreed to offer them electronic access to their office notes. Patients were surveyed online before and after the intervention. To permit comparisons between preintervention expectations and actual experiences, postintervention surveys were based largely on the baseline surveys. Postintervention data collection occurred after approximately 1 year of exposure to open notes. At BIDMC, 10355 patients finished the intervention with 6678 providing postintervention surveys. With this original data pool of preintervention and postintervention surveys, we started our evaluation by probing for note availability/reading frequencies (figure 2). Besides freetext examination in the original survey data set, we also interviewed individual BIDMC patients who had read multiple notes during and after the original study period. For our study, we applied several qualitative methodologies and standards: grounded theory formation/grounded hermeneutic approach, crystallisation/ immersion techniques, content analysis and multiple triangulation measures including member checking on various levels. ${ }^{53-63}$ 


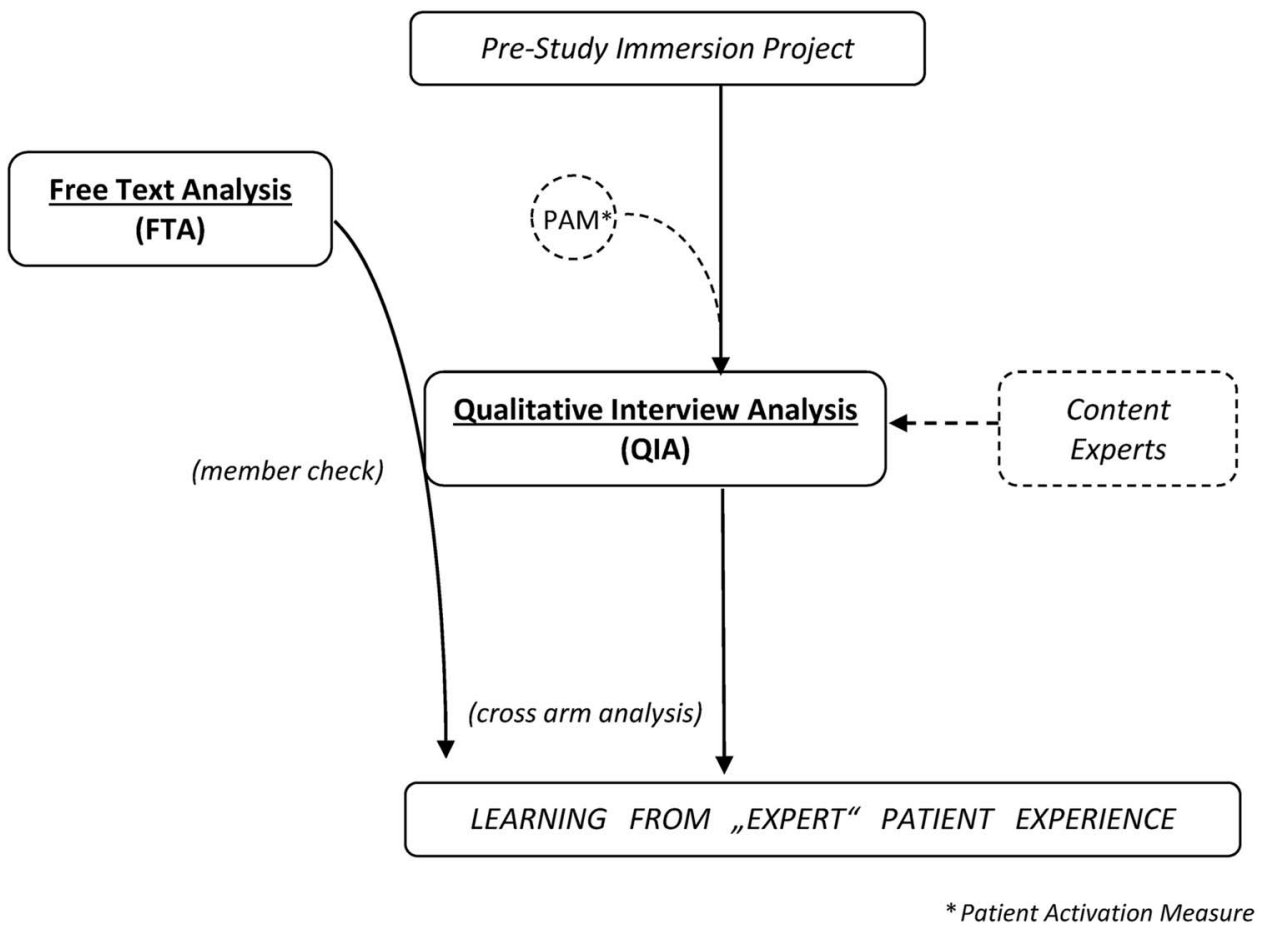

Figure 1 Study design-Data analysis and triangulation sequencing. Approach: mixed methods—qualitative. Left side illustrates the survey arm of the study (analysis of OpenNotes survey data: free-text analysis); centre/right side depicts the interview arm of the study (analysis of qualitative interviews with OpenNotes 'experts'); both arms interact (inform) and finally merge into each other-for further explanation, see text. Abbreviations: FTA, free-text analysis; QIA, qualitative interview analysis.

We began with a prestudy immersion project ${ }^{64}$ (see online supplementary appendix 1 ). We developed a list of 100 questions to derive key points for exploration. The immersion project yielded the structure for the interview guide.
Our study contained two arms, an analysis of the freetext survey responses (FTA) arm and an evaluation of the qualitative interviews (QIA) arm (figure 1). Seeking insights into patients' expectations and experiences, in the FTA arm, we examined patients' free-text responses

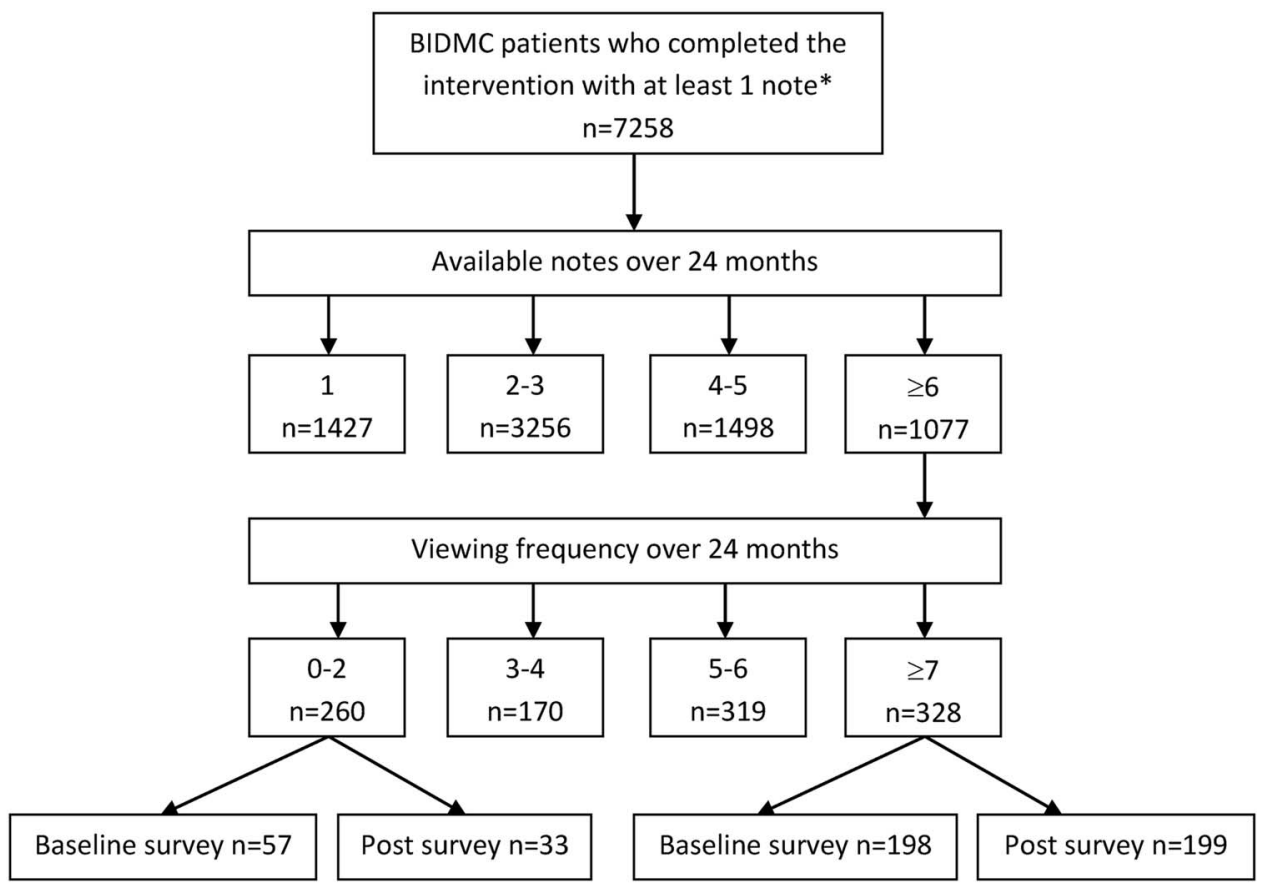

Figure 2 Patient/Survey flow-free-text analysis project (FTA). *Totals include only initial note and progress note (other notes/ contacts such as telephone or letter not counted). Abbreviation: BIDMC, Beth Israel Deaconess Medical Center (Boston). 
both in baseline (expectations) and postintervention (experiences) surveys collected before and after the original study period (see online supplementary appendix 2). We included responses from patients who had access to at least six notes from the start of the OpenNotes intervention until 1 year after its completion (24 months). Among patients with $\geq 6$ notes available, we included comments from both those who had read at least 7 notes and those who had read 0-2 notes (figure 2). We iteratively analysed these comments and created a codebook using inductive methodology and constant content analysis ('analytic induction'). ${ }^{65} 66$ During this process, we kept baseline and postintervention data separate, as well as data from low and highfrequency users, and started our analyses with baseline data, then going through the various data subsets (low and high-frequency users at pre- and at postintervention, respectively). Once the codebook was formed and stable, following various iterative cycles of data examination (starting with all portions of data subsets, then examining the entire data at a stretch), we again analysed and then coded the complete data set, thereby creating a comprehensive picture of the free-text survey content. In order to still allow for distinct views and comparisons, for example, between low to high users and pre to post data, we set up a quantitative descriptive analysis of code counts and frequencies in the various subgroups. For this analysis, we used Atlas.ti, V.7.

In the qualitative interview analysis (QIA) arm, we conducted semistructured, in-depth, face-to-face interviews with English-speaking 'heavy user' patients, defined as those who read at least 8 notes in a 24-month period. We recruited these patients as information-rich key informants ${ }^{67}$ by sequential inclusion from a purposive sample (figure 3). We stopped these interviews when we reached thematic saturation. The interviews focused on engagement and self-care, and each patient completed the patient activation measure (PAM-13) survey. ${ }^{68} 69$ All interviews were conducted in 2014 (February-March) in Greater Boston and were recorded and transcribed verbatim using a transcription service. Additional field notes were taken during the interviews.

The QIA and FTA were followed by a data consolidation/reconciliation phase (figure 1). This cross-arm analysis combined the two arms as we searched for a richer understanding of key themes.

TE and BP performed the data analysis and coded independently, using different styles for each target population and research objective (eg, immersion/crystallisation, editing and template). We used multiple measures of triangulation to ensure credibility, dependability, transferability and reflexivity. We asked three PCPs (2 female, 1 male, age 44-56) with extensive OpenNotes experience (working with it for $>40$ months, independent of the research team) to serve as content experts (figure 1).

In an attempt to avoid 'socially desirable' comments in favour of the OpenNotes initiative, the interviewer (TE)

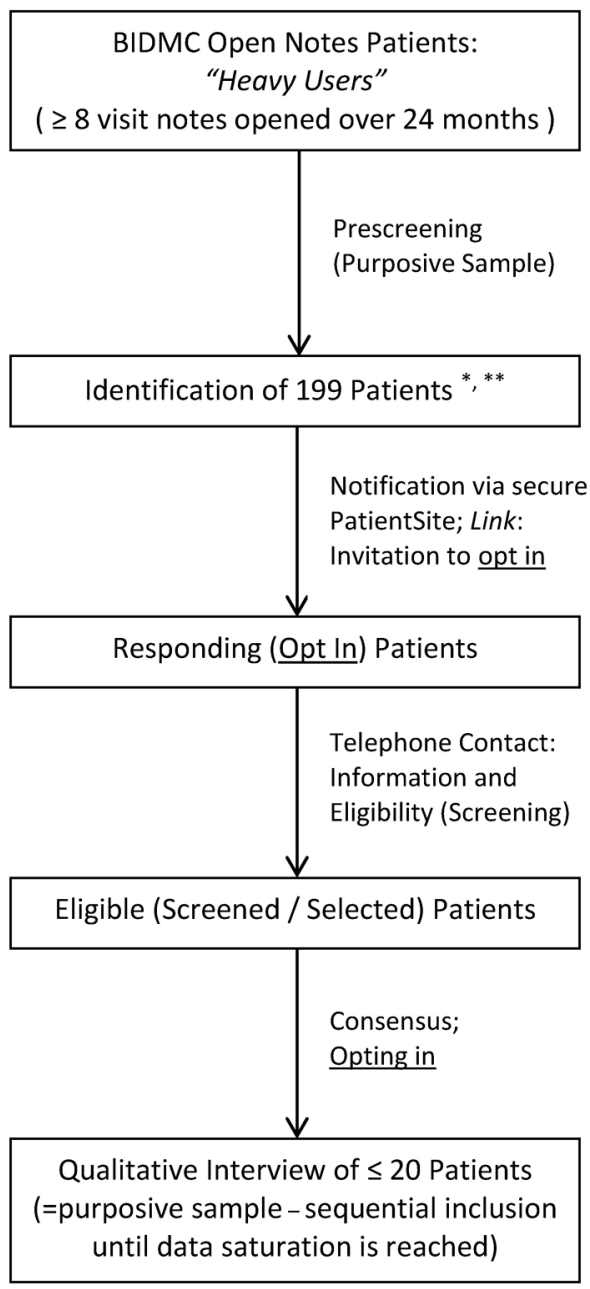

Figure 3 Recruitment chart for qualitative interview analysis project (QIA). *Median notes available=10 (IQR: 9, 12).

${ }^{*}$ Median notes viewed=9 (IQR: 8, 11). Abbreviations: BIDMC, Beth Israel Deaconess Medical Center (Boston); QIA, qualitative interview analysis.

stressed his neutrality and independence at the start of each interview session. In addition, to avoid 'framing effects', he provided no inside information (such as scientific data or recent or unpublished evidence).

All study procedures were approved by the institutional review board (IRB) of the Beth Israel Deaconess Medical Center, Boston.

\section{RESULTS}

Themes from the survey arm (FTA)

A total of 487 patient surveys met our inclusion criteria (figure 2), and these were analysed for free-text content. The number of utilisable free-text answers was 576 (female: 414, male: 162; age: 23-88 years), with a word range of 2-416; the majority of answers ranging from 50 to 150 words. During our analysis, we identified 1980 codes that then populated the codebook that emerged in the iterative analytic process (see online supplementary appendix 3). We made adjustments to 
the codebook until we achieved saturation. Inter-rater reliability was 0.977 after the first round, and 1.0 after the second round of reconciliation. A third independent coder, who was prepared to step in in case of unsettled incongruities, was not mobilised.

Five themes were identified: understanding, relationship, quality, self-care and improvements for the future, with up to 15 distinct codes in each domain (figure 4). The most frequently cited codes addressed the use of clinical notes for refreshing memory, improved understanding of one's own health information, and confirmation of one's understanding (figure 5). Patients also frequently reported improved trust in the physicianpatient relationship and better quality through using the notes as a reference. Adherence and compliance were also reported as enhanced due to improved clarity of health information. In the self-care domain, increased patient-centredness and a greater sense of control (reduced helplessness) were most frequently cited. Finally, regarding future improvements, a wish for more or all doctors to participate in the OpenNotes movement was predominant.

Quantitative-descriptive analysis (table 1, online supplementary appendix 4) demonstrated that more experience with open notes correlated with fewer concerns and more perceived benefits. Compared to those who had read 0-2 notes, high users (those who had read at least 7 notes) reported less confusion or fewer safety and privacy concerns, along with an increase in trust, motivation and feeling of control. Female patients differentiated themselves from male patients by more frequently mentioning better understanding of their doctor's work (and higher appreciation of their skills), together with an increased ability to refresh memories of visits as a benefit of reading notes. Patients with mental disorders (defined as 2 visits with a diagnosis of psychosis, depression, anxiety or substance abuse; or one visit with a prescription for a psychiatric medication) wrote more frequently about better communication with their doctors, better care coordination, and increased ability to self-manage and self-coordinate (including decreased feelings of stress/challenge or distraction during visits) than did patients without mental disorders. Compared to those in better health, people who reported fair/poor health more frequently described better care coordination as a result of reading notes. Activation and engagement as general aspects of the patient experience with open notes were mentioned in particular by those who had reported fair/poor health conditions prior to the actual experience (at study baseline), in addition to those who reported good health at the end (compared to excellent/very good or fair/poor at this point). Non-white patients more often reported better clarity of health information, higher motivation about their health and increased confidence and encouragement.

\section{Themes from the interview arm (QIA)}

Thirteen patients were interviewed (table 2). The average length of interviews was $40 \mathrm{~min}$. We administered the PAM questionnaire at the end of each patient interview; it took an estimated additional $7 \mathrm{~min}$.

Analysis of the transcripts confirmed the codebook and its themes (see online supplementary appendix 5).

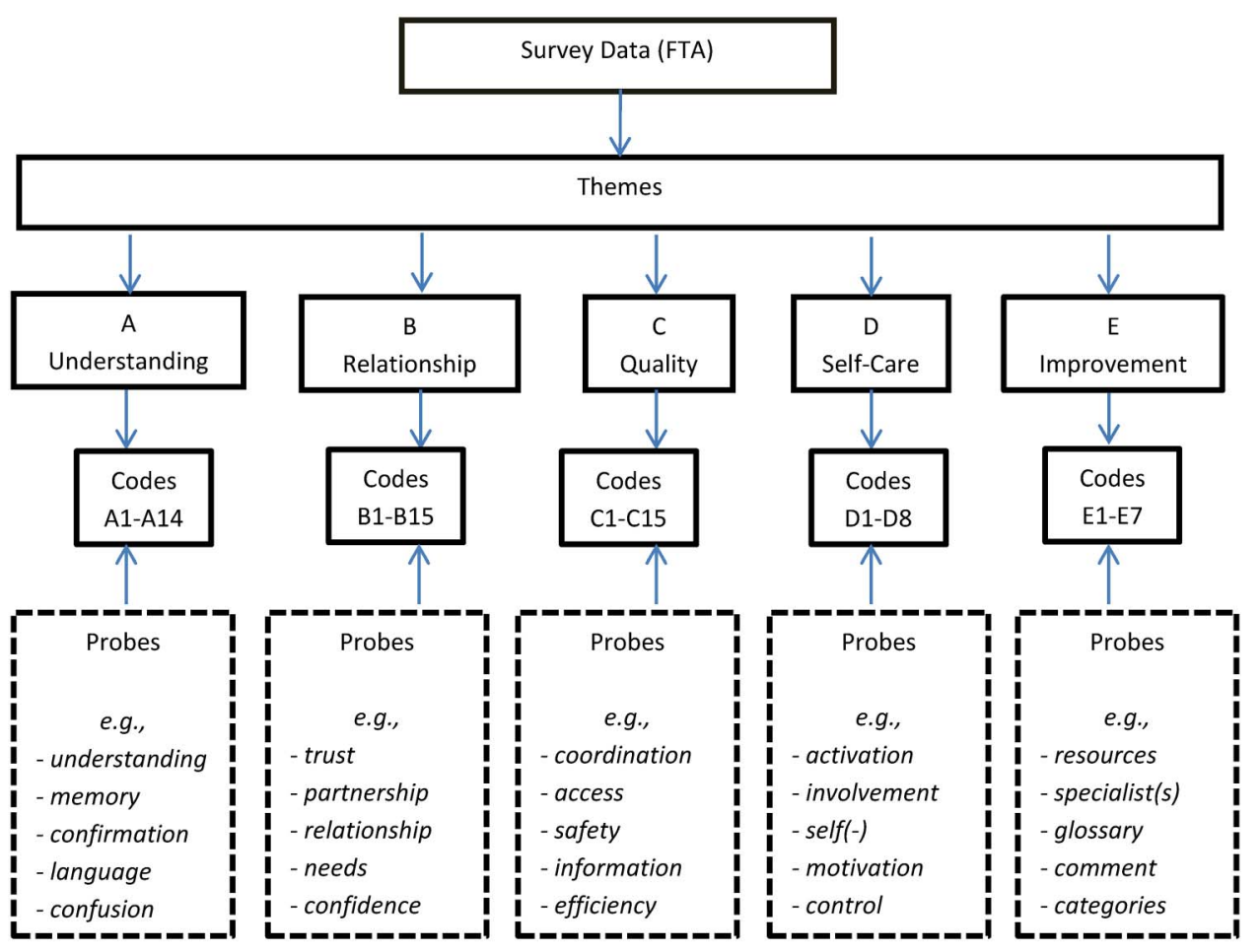

Figure 4 Overview of theme and code structure (theme-code identification). 
UNDERSTANDING $\uparrow[575]-$\begin{tabular}{ll|}
$\bullet$ & refreshing memory [104] \\
$\bullet$ & confirming understanding [94] \\
$\bullet$ & understanding one's own health information [77] \\
\hline
\end{tabular}

RELATIONSHIP $\uparrow$ [396]

- trust (sign of; elicitation, enhancement thereof) [55]

QUALITY $\uparrow[502]$

- keeping track/record (notes: reference) [74]

- adherence \& compliance (clarity of health information) [64]

SELF-CARE $\uparrow[334]$

- patient-centeredness (patient: proactive/partaking role) [60]

- control (reduced helplessness) [59]

FUTURE [173]

- more/all doctors participate [60]

Figure 5 Overview of frequency analysis. Most frequently checked codes from codebook-results from free-text answers/survey data $(\mathrm{FTA})$, organised on per domain/theme basis. Left side $=$ themes (domains); right side $=$ codes. Numbers depicted in square brackets reflect the numbers of identified codes (with the numbers on the left side-following each theme-expressing sum scores=absolute numbers of identified codes per theme; the numbers on the right side-following each depicted codeexpressing how often a specific code was identified). Note: Arrows behind each theme indicate the overall direction of reported effects (in this case: improvements/increase in all domains following/in view of OpenNotes practice).

Table 1 Overview of quantitative-descriptive analysis* results

\begin{tabular}{|c|c|c|}
\hline These patients & More often described these impacts & Than these patients \\
\hline $\begin{array}{l}\text { With experience } \\
\text { (at study end) }\end{array}$ & $\begin{array}{l}\text { Seeing/reporting more benefits } \\
\text { Less concerns }\end{array}$ & Without experience (at baseline) \\
\hline Read $\geq 7$ notes & $\begin{array}{l}\text { More reassurance/confirmation } \\
\text { Feeling that the doctor understands the patient better } \\
\text { Decreased confusion } \\
\text { Better trust in the doctor } \\
\text { Patient-doctor relationship strengthened } \\
\text { Increased experience of transparency (as a quality indicator) } \\
\text { Fewer safety/privacy concerns } \\
\text { Better keeping track of health information } \\
\text { Feeling more engaged } \\
\text { Feeling more motivated about their health } \\
\text { Feeling more in control }\end{array}$ & Read 0-2 notes \\
\hline Women & Better refreshment of memory (of visits) & Men \\
\hline $\begin{array}{l}\text { With Mental Health } \\
\text { problems }\end{array}$ & $\begin{array}{l}\text { Better communication with doctors } \\
\text { Experiencing higher coordination of care } \\
\text { More self-management and self-coordination } \\
\text { Feeling less challenged/distracted during visits }\end{array}$ & Without Mental health problems \\
\hline Fair/poor health & $\begin{array}{l}\text { Experiencing higher coordination of care } \\
\text { More self-care }\end{array}$ & Good to Excellent Health \\
\hline Non-white & $\begin{array}{l}\text { Increased confidence, feeling secure/well-cared for } \\
\text { More clarity of health information, adherence/compliance } \\
\text { Feeling more motivated about their health } \\
\text { Feeling actively encouraged }\end{array}$ & White \\
\hline
\end{tabular}


Among these high users, few reported safety and privacy concerns (two of 13 interviewees), and four reported sharing their notes with others. Some expressed the possibility of withholding information during visits because of worries about others gaining undesired access. The overall patient experience was characterised with terms of transparency, trust, easy access, efficiency, health benefits, harm avoidance, more involvement and feeling in control. Patients wanted more interactivity of notes, for example, the option to comment on notes or give input to have errors corrected. High users usually read single notes once or twice. The idea of an 'embargo' or delay in releasing notes was mentioned frequently, either for protecting patients from reading notes that could be overwhelming at a given moment, or to make sure that they would not accidentally read 'bad news' online before seeing their doctor in person.

High-use patients appeared strongly motivated, involved, active and engaged in their care. This group had a positive attitude towards self-care; at least $75 \%$ of the codes from the self-care domain of our codebook were met (checked) in all 13 interviews, and a third of them explicitly matched with $100 \%$. However, this finding was not always consistent with the PAM-13 scores (Table 2). For example, patients could conform to eight of eight self-care codes but still be placed in lower PAM ranges. Data analysis revealed that current medical condition (eg, facing chronic disease) and education (eg, professional academic background) are examples of factors that may have exerted influence on PAM scores: agreement with activation measures (as measured by PAM) did not in every case correspond to individual engagement reports and self-care approval (eg, interview analysis suggested higher activation scores for some participants).

\section{Themes from cross-arm analysis}

We performed a structured examination 'acrossmethods' to gain a more detailed and robust picture.

\section{Overall experience, individual use and constraints}

Frequent users of open notes were strongly in favour of an open, transparent and candid communication style, with easy access and high availability for them, but they still wanted to have personal and individual face-to-face time with their doctors as the primary means of communication. Patients wanted their doctors to tell them of serious or potentially stressful information and expressed caution towards 'automated' openness that might antedate contact with the doctor ("I guess my concern would be reading something at a time where you are physically not prepared to deal with what actually happened."). Patients described also how they felt 'empowered' or 'reassured' and used open notes in particular to refresh their memories of particular medical encounters, or generally as a 'memory aid' to track their health information ("I look at OpenNotes as a reassuring memory aid.").

\section{Trust}

Enhanced trust-regarded as a key part of an improved patient-physician relationship-was frequently reported ("I think it's important to know that I'm trusted as part of this relationship. And it helps me trust the doctor as well."). This was particularly true for female patients, patients without mental health problems and older patients. Self-rating of fair or poor health was also correlated with higher trust.

\section{Clarity, error detection and correction}

Better clarity of health information (reading notes resulted in better clarity) was often mentioned, particularly by patients with mental health problems, older patients and non-white patients. Clarity included clearor clarification of-instructions, possibly improving adherence to and compliance with medications. In addition, almost all interviewed patients mentioned the experience of detecting errors in the notes, mostly nonmedical or minor, and they usually did not contact the

Table 2 Descriptive data/study population-Characteristics of Interview Participants (QIA)

\begin{tabular}{|c|c|c|c|c|c|}
\hline Participant ID & PAM score (level) & Age & Gender & Education & SR H \\
\hline 004 & $45.3(1)$ & 87 & $\mathrm{~F}$ & $+c$ & OK \\
\hline 018 & $55.6(3)$ & 82 & $\mathrm{~F}$ & $+\mathrm{C}$ & OK \\
\hline 011 & $60.6(3)$ & 75 & $M$ & $+\mathrm{C}$ & Excellent \\
\hline 014 & $60.6(3)$ & 58 & $\mathrm{~F}$ & $-c$ & OK \\
\hline 009 & $63.1(3)$ & 67 & $\mathrm{~F}$ & $-c$ & OK \\
\hline 010 & $63.1(3)$ & 66 & $\mathrm{~F}$ & $-c$ & OK \\
\hline 012 & $63.1(3)$ & 66 & $M$ & $+\mathrm{C}$ & Excellent \\
\hline 003 & $65.5(3)$ & 66 & $\mathrm{~F}$ & $+c$ & OK \\
\hline 005 & $65.5(3)$ & 67 & $M$ & $+\mathrm{C}$ & Poor \\
\hline 016 & $65.5(3)$ & 69 & $F$ & $+\mathrm{C}$ & OK \\
\hline 017 & $75.0(4)$ & 60 & $\mathrm{~F}$ & $+\mathrm{C}$ & Excellent \\
\hline 013 & $84.8(4)$ & 73 & $\mathrm{~F}$ & $+\mathrm{C}$ & Excellent \\
\hline 006 & $90.7(4)$ & 77 & $M$ & $+C$ & OK \\
\hline
\end{tabular}


doctors about errors, at least not before a next visit. Nearly all interviewed patients reported that reading notes led them to correct their therapeutic regimen in some way, with most changes focusing on medication intake. As examples, patients mentioned correcting wrong dosages or times of medication intake as a result of reading their notes. Patients frequently mentioned the OpenNotes initiative as having health benefits by possibly helping them avoid harm and improving the quality of their care. While virtually all patients found notes containing errors in documentation or medical instructions, they found them only on occasion (happening, as patients reported, only once or twice over the 2 years). As examples: "I discovered that the doctor has misunderstood something I said.", "It ... sometimes clarifies my need and use of medications.", "I was [online] and happened to see that I was taking the wrong amount of prescription.", "The biggest benefit I see is being able to ... double check."

\section{Sharing, coauthoring notes and withholding information}

The majority of frequent note users in our analyses did not share their notes, using them primarily for their own record-keeping. When sharing occurred, this often happened with health professionals within the (extended) family. Some patients mentioned the possibility of actively withholding information during a visit because of the chance of other people reading it, especially when visits included discussions about their spouses or family. Some noted that open notes could produce more efficient and structured, yet less 'private' visits, and views differed on whether this represented a loss or gain. Frequent users seemed eager to comment on notes, or have parts changed/adjusted ('customised'). While some desired an option to approve a note, coauthoring of notes was not their first choice. "I just don't want anyone to share it. ... That's my own personal thing.", "I had it in writing for extended family to see also.", "The patient should have an opportunity to comment, and the doctor give feedback."

\section{Self-care, control and engagement}

These high users reported feelings of control and reduced helplessness, as well as active encouragement (feeling encouraged through reading the notes to take care of oneself or reflect on a visit and ask self-reliant questions). Control came up particularly for patients with mental health problems, with poor or fair health, and for men. These patients also referred to their ability to self-coordinate through the use of open notes. Patients described open notes as a stimulus or tool for helping them understand the importance of their playing an active, part-taking ('patient-centered') role in their own care. Member checking through individual interviews, however, revealed a distinction between patient-centredness as a 'whole person' (feels that the 'system' is built around the individual patient) and the actual experience of 'being at the centre of concern', which referred more to the actual problem that a patient presented, and how it was addressed. For the frequent users, their personal engagement seemed linked to the actual use of this tool. However, frequent users were not 'obsessive' about reading their notes; reading each note usually occurred once or twice. Additionally, frequency of reading was not correlated with self-rated health of patients. Overall, patients who felt more in control, more motivated, and had better understanding of their health, may have translated these sentiments into better self-management abilities. Quotes: "I take an active role ... that's a tool to make that happen.", "It made me feel ... proactive ... and not just reacting.", "I want to know what's happening. I want to be right at the forefront.", "I am at the center of concern. I am not powerless."

\section{DISCUSSION}

Not surprisingly, frequent users of open notes reported positive experiences, with commentaries that suggest that patient activation and engagement may be fostered in important ways. Drawing on free-text commentary and detailed encounters with patients who have used open notes frequently over a couple of years, our analyses suggest that as patients reflect on the experience, their thoughts fall into five themes (domains) that focus on understanding, relationships, quality, self-care and hopes for the future. Within these themes, understanding came up most frequently, with emphasis on using doctors' notes for refreshing memory and improving or confirming understanding of one's own health information. In addition, patients pointed to increased trust, improved management of medications, and a stronger sense of control, and they hoped that easy access to doctors' notes would become more widespread.

These findings complement other studies. Earnest et $a l^{70}$ reported that of all medical record components offered online, patients with congestive heart failure accessed their visit notes the most and felt empowered by this option. Patients in studies by Bjoernes $e t a t^{41}$ and Pagliari $e t a l^{31}$ were positive about experiences with open medical records, reporting improved communication and trust between patients and professionals, confidence in self-care, compliance and accuracy of records (also see Pyper et $a l,{ }^{71}$ Honeyman et $a l,{ }^{72}$ Woods et $a l,{ }^{49}$ Nazi et $\left.a \tilde{l}^{0}\right)$. In addition, Pyper et al attributed transparent clinician-patient interaction through personal health records to enhanced patient responsibility, participation and knowledge, overall health and quality of life, improved accessibility and relationships with health professionals, better care collaboration, and decreased errors and costs.

Two-thirds of the high-use patients in our study chose not to share notes with others. Despite multiple office visits, these patients were well enough to complete online surveys and to be interviewed. Perhaps reading notes is particularly important to those who, despite 
high utilisation, manage their own health without support from other caregivers. This population of high users also demonstrated high affinity towards self-care and active engagement. Code frequency analysis in the self-care domain and individual interviews revealed that this subset of patients is strongly motivated, active and engaged in their care.

Importantly, this finding was not always reflected in the PAM-13 scores, leading to the hypothesis that for a patient with chronic illness and debilitating limitations, a positive attitude towards self-care may need to be distinguished from actual ability to be active and selfengaged. Physical or situational factors, above and beyond engagement and activation formally assessed by PAM, may be of prime importance in this context. However, Mosen et $a l^{73}$ tested PAM among adults with chronic conditions and found that patients with high scores were more likely to perform self-management behaviours or report high medication adherence, compared to patients with the lowest scores. This needs to be examined more thoroughly in future studies.

Another aspect that deserves more attention in future research is the applicability of open notes to target groups. Previous studies ${ }^{48}$ found, for example, that about one-third of the overall study population had privacy concerns, but this was not reflected in the subset of high users examined in our study (about 15\%), suggesting that ongoing use of open notes might decrease privacy concerns over time. Patient comments in interviews also support this view. Some researchers, however, assume underreporting of safety or privacy concerns in the context of EHR use. ${ }^{74}$ Despite some patients truly experiencing challenges, they, in general, seem to value, benefit from and report predominantly positive experiences with health record transparency and the open sharing of notes. ${ }^{49} 50$ The area of privacy and a possible relation to frequency of use, or burden of illness, needs further study.

Our findings are primarily hypothesis generating, and they are clearly limited in terms of generalisability, but we believe they carry some weight. We approached the research questions from multiple perspectives, combining different study arms and techniques. With formally developed design and measures, including prestudy explorations to support the construction of interview guides, our goal was both to reflect and refer to the full body of existing literature and knowledge in the field. In addition, we combined analyses of free-text survey data with qualitative interviews in which purposefully selected information-rich study participants offered insights on the patient experience. We were guided by the standards of data triangulation, analysis and legitimation and tried to minimise biases.

Despite all these efforts, the possibility of biased conclusions persists. Participants in the study differed from a majority of patients nationally by virtue of having registered on secure electronic patient portals. Moreover, we included patients from only one health system (BIDMC). This may also have caused health literacy and educational biases, which should be more thoroughly addressed in future studies. Since the interviewer (TE) was a doctor, patients may have offered responses different from what might have been elicited by a non-medical interviewer. Finally, attitude towards 'their' hospital, or 'their' doctor, or the use of the secure patient portal in general, or EHR use, may have affected responses (halo effects should be considered in both directions).

Our results highlight some areas for additional consideration. Some patients reported withholding information to avoid the chance that others might see it. Some wanted delayed access in order to allow time for bad news to be relayed by their doctors before reading it in the note. Some wanted to comment on notes or to correct them. To the best of our knowledge, portals and electronic medical records cannot currently handle individual patient preferences such as who can see what, or interactivity allowing commentary or other input from patients. We will need to develop these capabilities to be responsive to engaged and activated patients.

The OpenNotes movement has now spread to a growing number of organisations around the USA and has extended beyond primary care to include medical and surgical specialists, professionals focusing on mental disorders, nurses, physical therapists and other clinicians. ${ }^{75}{ }^{76}$ As the practice spreads, both consumers and health professionals have called for open notes to become the standard of care. ${ }^{47} 77$ In 'traditional' practice (not providing patients with online access to their notes), $50 \%$ of patients may leave office visits without an adequate recall or understanding of what the physician has told them. ${ }^{78}$ The American College of Physicians now expects increased transparency through open notes and improved clinical documentation, also calling for broad-based efforts for patient education, explaining, for example, that a good medical note should be accurate but brief, and not a verbatim transcript of clinical interaction. ${ }^{79}$ Also, in examining missed and inappropriate diagnoses, the Institute of Medicine has recently recommended the adoption of open notes, in an attempt to mobilise patients and their families as active witnesses and evaluators of care. ${ }^{80}$

\section{CONCLUSIONS}

Open notes may increase patient activation and engagement in important ways. Patients in this evaluation suggest that reading notes helped improve their understanding of health information, fostered better relationships with doctors, improved the processes of care, and helped with self-care. They are also interested in becoming involved more actively in the generation of their medical records. As the use of fully open and transparent medical records spreads, it is important to gain a deeper understanding of the possible benefits or harms, and to characterise target populations that may require varying modes of delivery. Studying and exploring these aspects more deeply in the future will be important for 
developing a richer understanding of the effects of fully transparent records. However, for now, comments from one of the patients seem sensible:

"I do think that transparency is key and is quality of care. I think it's important for patients to understand truthfully what their situation is and how they can help themselves and be educated enough to be able to ask the right questions to physicians. Every patient has that right ... and I think that OpenNotes helps that.”

Acknowledgements The authors thank the Commonwealth Fund, Robin Osborn, Bradford $\mathrm{H}$ Gray and Dana Sarnak for their helpful comments on the presentation slides and draft presentation; Suzanne G. Leveille for helpful discussions in study planning, design and data interpretation; Judith Hibbard for help with licensing and interpreting the Patient Activity Measure (PAM); Anne Becker, Leslie Curry, Kelly Devers and Jeff Borkan for their methodological support; Jan Frich for discussing triangulation and legitimation measures; Jon Darer for discussing future implications and strategies; Anna Johansson for helping as an IRB navigator at BIDMC; colleagues from the BIDMC OpenNotes research team and additional external scholars (key informants) who participated in prestudy inquiries and subsequent member checks (team survey). Most importantly, the authors thank all study participants.

Contributors TE, JW and TD conceived the study. TE, JW and TD were involved in designing the study and developing the methods. TE, JW and TD obtained funding. TE coordinated the conduct of the study and conducted the interviews, and together with BP read the survey and interview data (transcripts), developed the analytical framework/coding, and codebook, as well as performed the primary qualitative, and quantitative analyses with technical support of Atlas.ti software. RM was involved in statistical analyses and, together with MA in study administration, including patient recruitment and steering. TE led the secondary and final analysis, with substantial contributions from JW and TD, including data interpretation, organisation of findings. TE, JW, and TD drafted the manuscript. All authors critically revised the manuscript. TE, JW and TD are guarantors. All authors had access to the data. The lead author (TE) affirms that the manuscript is an honest, accurate, and transparent account of the study being reported; no important aspects of the study have been omitted; no discrepancies from the study as planned occurred.

Funding This work was supported by The Commonwealth Fund as part of the Harkness Fellowship grants to TE and BP. Support for the overall OpenNotes project was provided primarily by the Robert Wood Johnson Foundation. The views presented here are those of the authors and should not be attributed to the Commonwealth Fund, or its directors, officers or staff.

Competing interests All authors have completed the ICMJE uniform disclosure form at http://www.icmje.org/coi_disclosure.pdf (available on request from the corresponding author) and declare: no support from any organisation for the submitted work; no financial relationships with any organisations that might have an interest in the submitted work in the previous 3 years; no other relationships or activities that could appear to have influenced the submitted work.

Ethics approval The Committee on Clinical Investigations (CCI), which is the institutional review board (IRB) for the Beth Israel Deaconess Medical Center, Boston, approved this study (Protocol \#: 2009-P-000359/30; BIDMC). Each interview participant gave signed consent immediately before the interview.

Provenance and peer review Not commissioned; externally peer reviewed.

Data sharing statement No additional data are available.

Open Access This is an Open Access article distributed in accordance with the Creative Commons Attribution Non Commercial (CC BY-NC 4.0) license, which permits others to distribute, remix, adapt, build upon this work noncommercially, and license their derivative works on different terms, provided the original work is properly cited and the use is non-commercial. See: http:// creativecommons.org/licenses/by-nc/4.0/

\section{REFERENCES}

1. Ross SE, Lin CT. The effects of promoting patient access to medical records: a review. J Am Med Inform Assoc 2003;10:129-38.

2. Ridsdale L, Hudd S. What do patients want and not want to see about themselves on the computer screen: a qualitative study. Scan J Prim Health Care 1997:15:180-3.

3. Michael M, Bordley C. Do patients want access to their medical records? Med Care 1982;20:432-5.

4. Shenkin BN, Warner DC. Sounding board. Giving the patient his medical record: a proposal to improve the system. $N$ Engl $J$ Med 1973;289:688-92.

5. Delbanco T, Walker J. Patients should have easier access to their doctors' medical notes. Mod Healthc 2011;41:22.

6. Masys D, Baker D, Butros A, et al. Giving patients access to their medical records via the Internet: the PCASSO experience. J Am Med Inform Assoc 2002;9:181-91.

7. Goldberg HI, Tarczy-Hornoch $\mathrm{P}$, Stephens $\mathrm{K}$, et al. Internet access to patients' records. Lancet 1998;351:1811.

8. Feeley TW, Shine KI. Access to the medical record for patients and involved providers: transparency through electronic tools. Ann Intern Med 2011;155:853-4.

9. Steinbrook R. Personally controlled online health data-the next big thing in medical care? N Engl J Med 2008;358:1653-6.

10. DesRoches CM, Campbell EG, Rao SR, et al. Electronic health records in ambulatory care-a national survey of physicians. N Engl J Med 2008;359:50-60.

11. Jha AK, DesRoches CM, Campbell EG, et al. Use of electronic health records in U.S. hospitals. N Engl J Med 2009;360:1628-38.

12. DesRoches CM, Campbell EG, Vogeli C, et al. Electronic health records' limited successes suggest more targeted uses. Health Aff (Millwood) 2010;29:639-46.

13. Joseph S, Snow M, Furukawa MF, et al. HITECH spurs EHR vendor competition and innovation, resulting in increased adoption. Am J Manag Care 2014;20:734-40.

14. Patrick K. Patients and their medical records: it is time to embrace transparency. CMAJ 2014;186:811.

15. El-Kareh R, Gandhi TK, Poon EG, et al. Trends in primary care clinician perceptions of a new electronic health record. $J$ Gen Intern Med 2009;24:464-8.

16. Blumenthal $D$, Tavenner $M$. The "meaningful use" regulation for electronic health records. N Engl J Med 2010;363:501-4.

17. Ross AP. The case against showing patients their records. Br Med $J$ (Clin Res Ed) 1986;292:578.

18. Steiner P. Patient access to the medical record: a study of physician attitudes. Med Rec News 1978;49:77-8, 80-1.

19. Britten N, Bartholomew J, Morris R, et al. Consultant's and patient's views about patient access to their general practice records. $J R$ Soc Med 1991;85:284-7.

20. Fisher B, Britten N. Patient access to records: expectations of hospital doctors and experiences of cancer patients. $\mathrm{Br} J$ Gen Pract 1993;43:52-6.

21. Ross SE, Todd J, Moore LA, et al. Expectations of patients and physicians regarding patient-accessible medical records. J Med Internet Res 2005;7:e13.

22. Milton CL. Information sharing: transparency, nursing ethics, and practice implications with electronic health records. Nurs Sci $Q$ 2009;22:214-19.

23. Tang PC, Lee TH. Your doctor's office or the internet? Two paths to personal health records. N Engl J Med 2009;360:1276-8.

24. Cahill JE, Gilbert MR, Armstrong TS. Personal health records as portal to the electronic medical record. $J$ Neurooncol 2014;117:1-6.

25. Druss BG, Ji X, Glick G, et al. Randomized trial of an electronic personal health record for patients with serious mental illnesses. Am J Psychiatry 2014;171:360-8.

26. Dhanireddy S, Walker J, Reisch L, et al. The urban underserved: attitudes towards gaining full access to electronic medical records. Health Expect 2014;17:724-32.

27. Bronson DL, Constanza MC, Tufo HM. Using medical records for older patient education in ambulatory practice. Med Care 1986;24:332-9.

28. Bronson DL, Rubin AS, Tufo HM. Patient education through record sharing. QRB Qual Rev Bull 1978;4:2-4.

29. Maly RC, Bourque LB, Engelhardt RF. A randomized controlled trial of facilitating information giving to patients with chronic medical conditions: effects on outcomes of care. J Fam Pract 1999;48:356-63.

30. Ross SE, Moore LA, Earnest MA, et al. Providing a web-based online medical record with electronic communication capabilities to patients with congestive heart failure: randomized trial. J Med Internet Res 2004:6:e12.

31. Pagliari C, Detmer D, Singleton P. Potential of electronic personal health records. BMJ 2007;335:330-3. 
32. Ralston JD, Revere D, Robins LS, et al. Patient's experience with a diabetes support programme based on an interactive electronic medical record: qualitative study. BMJ 2004;328:1159-63.

33. Kern LM, Edwards A, Kaushal R. The patient-centered medical home, electronic health records, and quality of care. Ann Intern Med 2014;160:741-9.

34. Peeters JM, Wiegers TA, Friele RD. How technology in care at home affects patient self-care and self-management: a scoping review. Int J Environ Res Public Health 2013;10:5541-64.

35. Slack WV, Kowaloff HB, Davis RB, et al. Evaluation of computer-based medical histories taken by patients at home. J Am Med Inform Assoc 2012;19:545-8.

36. Bernstein RA, Andrews EM, Weaver LA. Physician attitudes toward patients' request to read their hospital records. Med Care 1981:19:118-21.

37. Feldman HJ, Walker J, Li J, et al. OpenNotes: hospitalists' challenge and opportunity. J Hosp Med 2013;8:414-17.

38. Institute of Medicine: Committee on Quality of Health Care in America. Crossing the quality chasm. A new health system for the 21st century. Washington DC: National Academy Press, 2001.

39. Häendel A, Jüenemann AG, Prokosch HU, et al. [Web-based electronic patient record as an instrument for quality assurance within an integrated care concept]. Klin Monbl Augenheilkd 2009;226:161-7.

40. Mold F, Ellis B, de Lusignan S, et al. The provision and impact of online patient access to their electronic health records (EHR) and transactional services on the quality and safety in health care: systematic review protocol. Inform Prim Care 2012;20:271-82

41. Bjoernes CD, Laursen BS, Delmar C, et al. A dialogue-based Web application enhances personalized access to healthcare professionals-an intervention study. BMC Med Inform Decis Mak 2012;12:96.

42. Zulman DM, Nazi KM, Turvey CL, et al. Patient interest in sharing personal health record information: a web-based survey. Ann Intern Med 2011;155:805-10.

43. Zulman DM, Nazi KM, Asch SM, et al. Access to the Medical Record. Ann Intern Med 2012;156:668.

44. Delbanco T, Walker J, Darer JD, et al. Open notes: doctors and patients signing on. Ann Intern Med 2010;153:121-5.

45. Leveille SG, Walker J, Ralston JD, et al. Evaluating the impact of patients' online access to doctors' visit notes: designing and executing the OpenNotes project. BMC Med Inform Decis Mak 2012;12:32.

46. Walker J, Leveille SG, Ngo L, et al. Inviting patients to read their doctors' notes: patients and doctors look ahead: patient and physician surveys. Ann Intern Med 2011;155:811-19.

47. Walker J, Meltsner M, Delbanco T. US experience with doctors and patients sharing clinical notes. BMJ 2015;350:g7785.

48. Delbanco T, Walker J, Bell SK, et al. Inviting patients to read their doctors' notes: a quasi-experimental study and a look ahead. Ann Intern Med 2012;157:461-70.

49. Woods SS, Schwartz E, Tuepker A, et al. Patient experiences with full electronic access to health records and clinical notes through the My HealtheVet Personal Health Record Pilot: qualitative study. $J$ Med Internet Res 2013;15:e65.

50. Nazi KM, Turvey CL, Klein DM, et al. VA OpenNotes: exploring the experiences of early patient adopters with access to clinical notes. J Am Med Infirm Assoc 2015;22:380-9.

51. Weinert C. Giving Doctor's Daily Progress Notes to Hospitalized Patients and Families to Improve Patient Experience. Am J Med Qual 2015. [Epub ahead of print].

52. Wright E, Darer J, Tang X, et al. Sharing Physician Notes Through An Electronic Portal is Associated With Improved Medication Adherence: Quasi-Experimental Study. J Med Internet Res 2015; 10:e226

53. Crabtree BF, Miller WL, eds. Doing qualitative research. 2nd edn. Thousand Oaks: Sage Publications, 1999.

54. Office of Behavioral and Social Sciences Research. Qualitative methods in health research. Bethesda: National Institutes of Health, 1999.

55. Giacomini MK, Cook DJ. Users' guides to the medical literature: XXIII. Qualitative research in health care A. Are the results of the study valid? Evidence-Based Medicine Working Group. JAMA 2000;284:357-62.

56. Giacomini MK, Cook DJ. Users' Guides to the medical literature: XXIII. Qualitative research in health care B. What are the results and how do they help me care for my patients? Evidence-Based Medicine Working Group. JAMA 2000;284:478-82.

57. Malterud K. Qualitative research: standards, challenges, and guidelines. Lancet 2001;358:483-8.

58. Shenton AK. Strategies for ensuring trustworthiness in qualitative research projects. Educ Inform 2004;22:63-75.

59. Tong A, Sainsbury P, Craig J. Consolidated criteria for reporting qualitative research (COREQ): a 32-item checklist for interviews and focus groups. Int J Qual Health Care 2007;19:349-57.

60. Creswell JW, Fetters MD, Ivankova NV. Designing a mixed methods study in primary care. Ann Fam Med 2004;2:7-12.

61. Miller WL, Crabtree BF. Clinical research: a multimethod typology and qualitative roadmap. In: Crabtree BF, Miller WL, eds. Doing qualitative research. 2nd edn. Thousand Oaks: Sage Publications, 1999:3-30.

62. Glaser BG, Strauss AL. The discovery of grounded theory. Chicago: Aldine, 1967.

63. Addison RB. A grounded hermeneutic editing approach. In: Crabtree BF, Miller WL, eds. Doing qualitative research. 2nd edn. Thousand Oaks: Sage Publications, 1999:145-62.

64. Borkan J. Immersion/Crystallization. In: Crabtree BF, Miller WL, eds. Doing qualitative research. 2nd edn. Thousand Oaks: Sage Publications, 1999:179-94.

65. Pope C, Ziebland S, Mays N. Qualitative research in health care. Analysing qualitative data. BMJ 2000;320:114-16.

66. Miles M, Huberman A. Qualitative data analysis. London: Sage, 1984.

67. Gilchrist VJ, Williams RL. Key informant interviews. In: Crabtree BF, Miller WL, eds. Doing qualitative research. 2nd edn. Thousand Oaks: Sage Publications, 1999:71-88.

68. Hibbard JH, Stockard J, Mahoney ER, et al. Development of the Patient Activation Measure (PAM): conceptualizing and measuring activation in patients and consumers. Health Serv Res 2004;39:1005-26.

69. Hibbard JH, Mahoney ER, Stockard J, et al. Development and Testing of a Short Form of the Patient Activation Measure. Health Serv Res 2005;40:1918-30.

70. Earnest MA, Ross SE, Wittevrongel L, et al. Use of a patient-accessible electronic medical record in a practice for congestive heart failure: patient and physician experiences. J Am Med Inform Assoc 2004:11:410-17.

71. Pyper C, Amery J, Watson M, et al. Patients' experiences when accessing their on-line electronic patient records in primary care. Br J Gen Pract 2004;54:38-43.

72. Honeyman A, Cox B, Fisher B. Potential impacts of patients access to their electronic records. Inform Primary Care 2005;13:55-60.

73. Mosen DM, Schmittdiel J, Hibbard J, et al. Is Patient Activation Associated With Outcomes of Care for Adults With Chronic Conditions? J Ambul Care Manage 2007;30:21-9.

74. Menon S, Singh H, Meyer AN, et al. Electronic health record related safety concerns: a cross-sectional survey. J Healthc Risk Manag 2014;34:14-26.

75. Walker J, Delbanco T. Interval examination: moving toward Open Notes. J Gen Intern Med 2013;28:965-9.

76. Kahn MW, Bell SK, Walker J, et al. A piece of my mind. Let's show patients their mental health records. JAMA 2014;311:1291-2.

77. Walker J, Darer JD, Elmore JG, et al. The road toward fully transparent medical records. N Engl J Med 2014;370:6-8.

78. Bodenheimer T. The future of Primary Care: Transforming Practice. N Engl J Med 2008;359:2086, 2089.

79. Kuhn T, Basch P, Barr M, et al. Medical Informatics Committee of the American College of Physicians. Clinical Documentation in the 21st Century: Executive Summary of a Policy Position Paper From the American College of Physicians. Ann Intern Med 2015;162:301-3 in press (doi:10.7326/M14-2128).

80. Balogh EP, Miller BT, Ball JR, eds. Improving diagnosis in health care. Washington DC: The National Academy of Sciences, The National Academies Press, 2015. 